$\int_{0}^{0} d^{1}$

AE

RESERPCH

AnIII

DEVELOPIIENT

REPORT

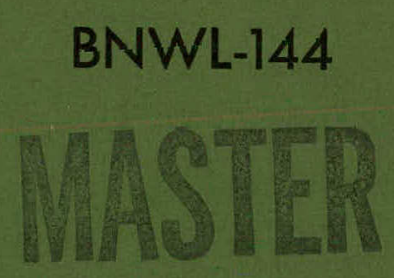

\title{
DETECTION OF RADIONUCLIDE CONTAMINATION ON FACE MASKS
}

5. M. SHEEN and G. D. CROUCH

SEPTEMBER, 1965

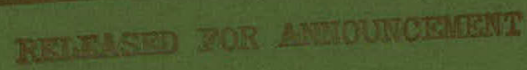

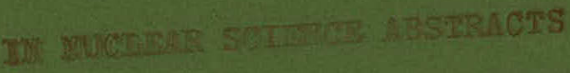




\section{DISCLAIMER}

This report was prepared as an account of work sponsored by an agency of the United States Government. Neither the United States Government nor any agency Thereof, nor any of their employees, makes any warranty, express or implied, or assumes any legal liability or responsibility for the accuracy, completeness, or usefulness of any information, apparatus, product, or process disclosed, or represents that its use would not infringe privately owned rights. Reference herein to any specific commercial product, process, or service by trade name, trademark, manufacturer, or otherwise does not necessarily constitute or imply its endorsement, recommendation, or favoring by the United States Government or any agency thereof. The views and opinions of authors expressed herein do not necessarily state or reflect those of the United States Government or any agency thereof. 


\section{DISCLAIMER}

Portions of this document may be illegible in electronic image products. Images are produced from the best available original document. 


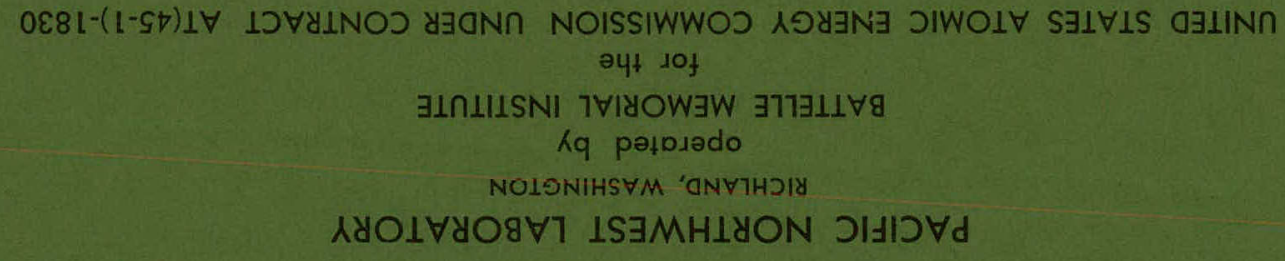

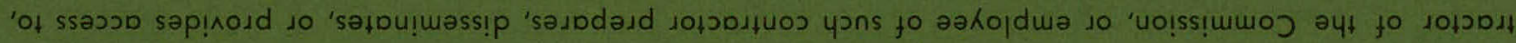

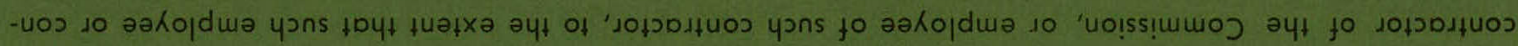

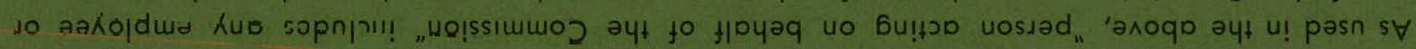

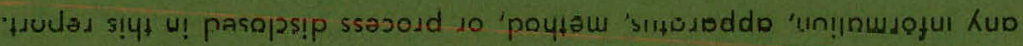

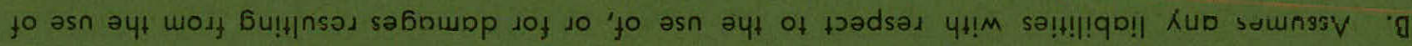

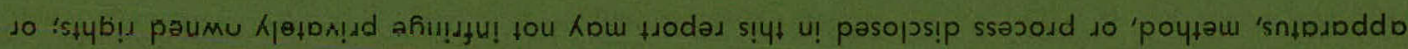

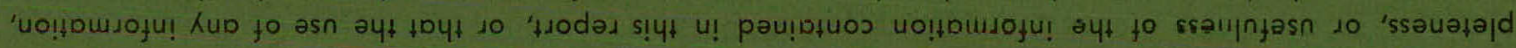

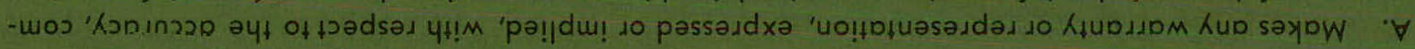

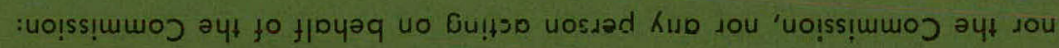

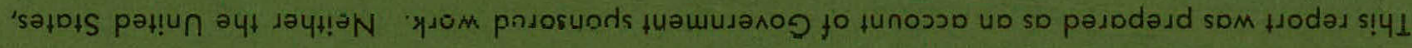


BNWL-1 44

UC-37, Instruments

FIRST
UNRESTRICTED
TID:4500
SEP 30 OSE
$\begin{gathered}\text { UISINISUTION } \\ \text { MADE }\end{gathered}$

DET ECTION OF RADIONUCLIDE CONTAMINATION ON FACE MASKS

\begin{abstract}
By
E. M. Sheen and G. D. Crouch

Instrument Research and Development Section.

Physics and Instruments Department
\end{abstract}

September, 1965

PACIFIC NORTHWEST LABORATORY RICHLAND, WASHINGTON 
Af .94

Printed in USA. Price $\$ 1.00$. Available from the Clearinghouse for Federal Scientific and Technical Information National Bureau of Standards

U.S. Department of Commerce Springfield, Virginia 


\section{DET ECTION OF RADIONUCLIDE CONTAMINATION ON FACE MASKS}

\section{INTRODUCTION}

This report describes a monitor which was developed to assure successful decontamination of face masks.

Protective clothing, such as laboratory coats, coveralls, and face masks, is used at Hanford in radiation zones to provide control for the possible spread of contamination and to prevent inhalation and ingestion of radionuclides. A prior report ${ }^{(1)}$ described a monitoring system developed for radiation surveying of laboratory coats and coveralls.

The face masks (termed "assault masks" at Hanford) are employed in certain plant locations to prevent inhalation and ingestion of betagamma emitting fission products. In the course of use, the outer surfaces, and occasionally the inner surfaces, of the masks became contaminated. During decontamination, it is necessary to monitor the surfaces of the masks to assure that the decontamination procedures have been successful. $\underline{\text { SUMMMARY }}$

An experimental monitoring instrument was developed to detect and measure fission product contamination on the inner and outer surfaces of protective face masks. The instrument includes two large scintillation detector assemblies employing light pipes to conform to mask surfaces and one smaller scintillation detector to monitor the nose piece of the mask. All circuitry employed is solid state. The instrument can detect 10 nanocuries $(10 \mathrm{nCi})$ of $\mathrm{Pm}^{147}$, a low energy beta emitter.

DISCUSSION

Surfaces of the masks are monitored simultaneously, by the instrument system shown in Figure 1, for beta emitters by three separate scintillation detcctor assemblies and counter channels. The employed scintillator chosen is a thin coating of anthracene (with binder), which is sprayed onto

(1) W. G. Spear and M. O. Rankin. Protective Clothing Monitoring System, HW-76351 REV. August 1, 1963. 
polished Lucite light pipes shaped to fit the mask contours. The scintillating material is covered with two layers of aluminized Mylar $\left(0.9 \mathrm{mg} / \mathrm{cm}^{2}\right.$ mass thickness).

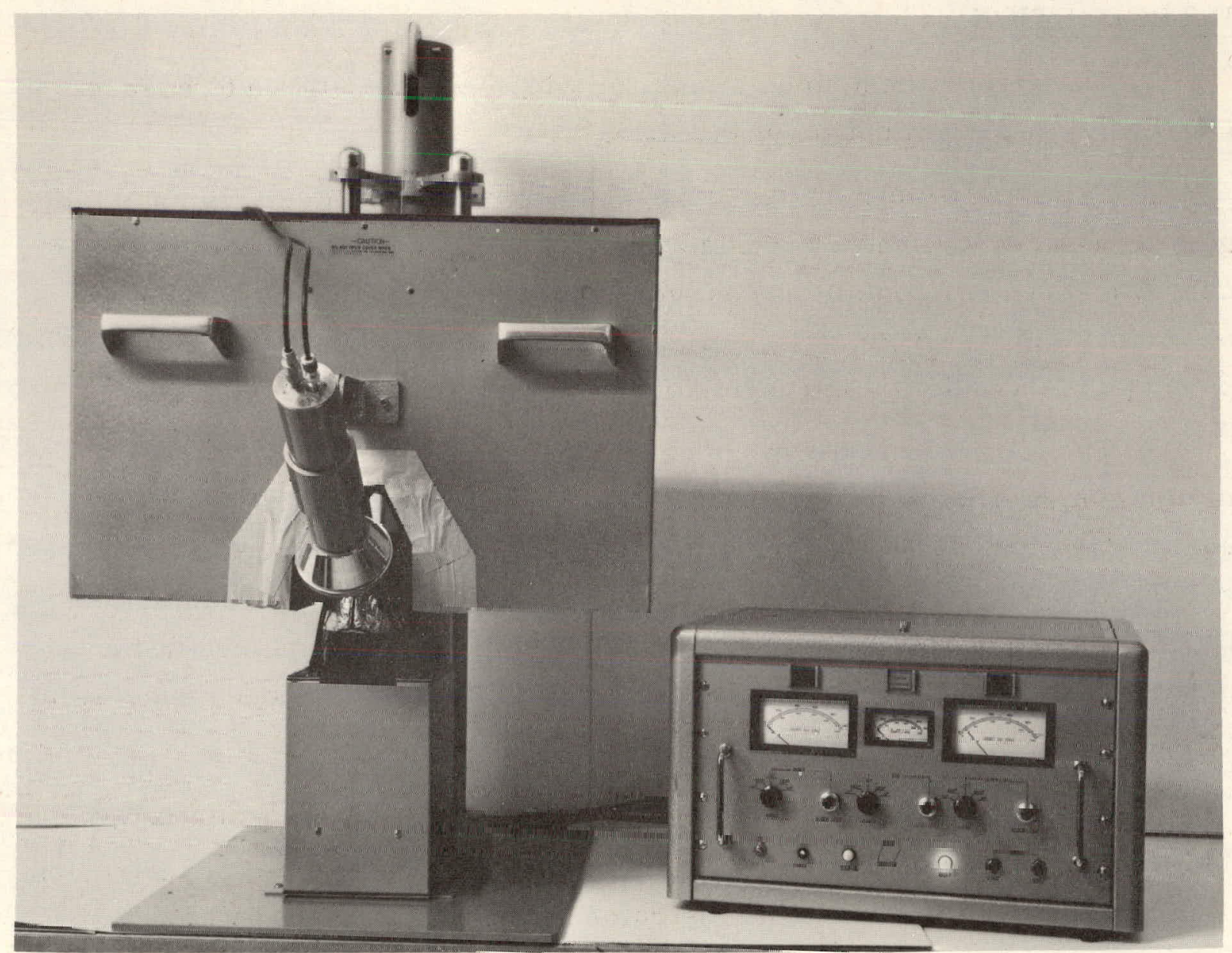

Neg. 0652088

\section{FIGURE 1}

Complete Instrumentation System

The mechanical arrangements of the major detectors are shown in Figures 2 and 3 . The mask to be monitored is placed over the lower (inner surface) probe, then the counterbalanced upper probe, which employs three detectors, is lowered gently over the outside of the mask. This action automatically starts the electronic counting and initiates a 15 sec time cycle. 


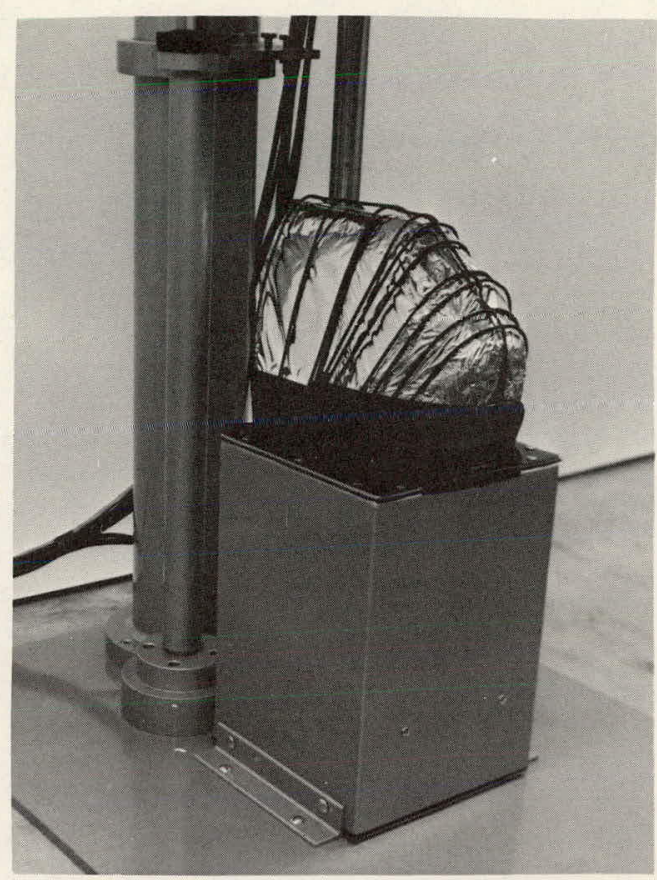

Neg. $38400-7$

\section{FIGURE 2}

Assembled Probe for Monitoring Inside Surface of Mask

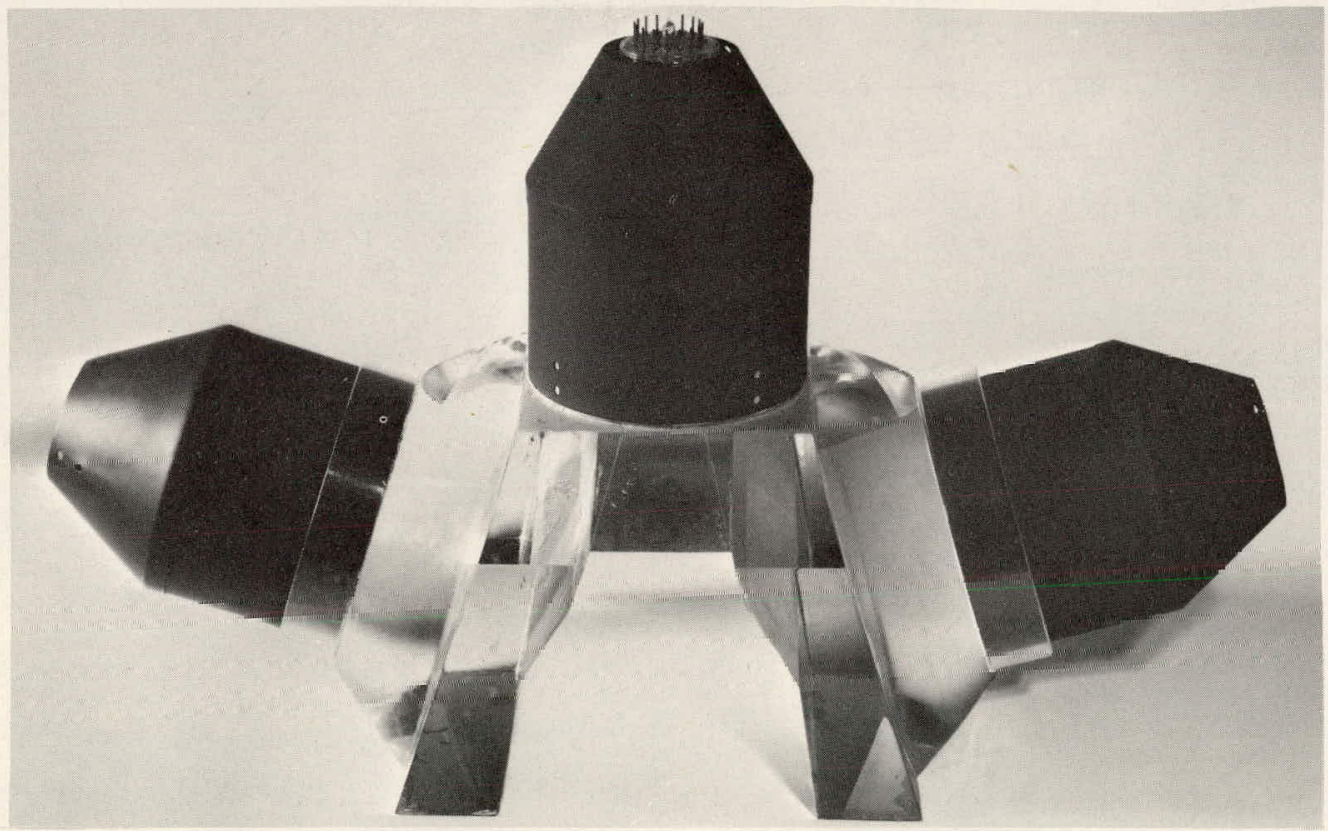

Neg. $0651687-2$

\section{FIGURE 3}

Probe Configuration (with Lucite Light Pipe) Used for Monitoring Outer Surface of Mask 
Beta particles losing energy in the anthracene cause visible light scintillations and the photons from these events impinge on the photocathodes of the multiplier phototubes * causing emission of photoelectrons. These are amplified in a multiplication fashion to provide output signal pulses from the phototubes. Pulses from the two large (upper and lower) detector assemblies and from the smaller nosepiece detector are counted in separate counting channels during the $15 \mathrm{sec}$ timing period. Suitable alarms are provided, and these energize if the count exceeds the alarm set points.

Table I describes the counting sensitivity for various radionuclides.

TABLE I

SYST EM SENSITIVITY

RADIONUCLIDE

(Source Strengths Shown in disintegrations/min)

\begin{tabular}{ccc}
$\mathrm{Pm}^{147}$ & $\mathrm{Ra} \mathrm{D}-\mathrm{E}-\mathrm{F}$ & $\mathrm{Cs}^{137}$, \\
$2.67 \times 10^{4}$ & $2.72 \times 10^{4}$ & $2.41 \times 10^{4}$ \\
\hline
\end{tabular}

$\underline{\text { BACKGROUND PLUS SOURCE }}$

Outer Surface Counts, $15 \mathrm{sec}$

600

640

640

Inner Surface Counts, $15 \mathrm{sec}$

630

680

650

Nosepiece Counting Rate,

1500

4000

3000

counts/min

\section{NET SOURCE}

Outer Surface Counts, $15 \mathrm{sec}$

220

340

260

Inner Surface Counts, $15 \mathrm{sec}$

330

380

350

Nosepiece Counting Rate,

1200

3700

2700 counts/min

The solid state electronics circuit diagram is shown in Figure 4 . A pulse preamplifier is located in each of the probes and pulses from each are amplified, noise discriminated, and counted for each channel by circuits in

* The nosepiece phototube is an EMI-9536B (3 in.). The other phototubes are EMI-9530B (5 in.). 


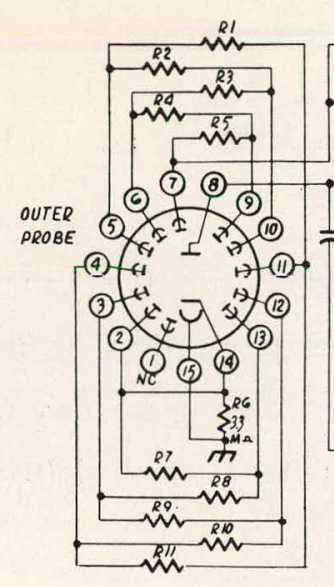

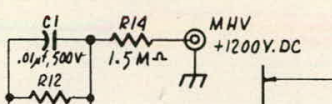

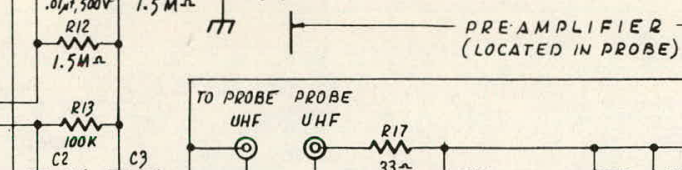

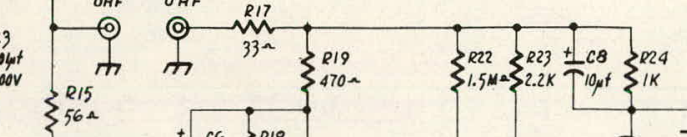

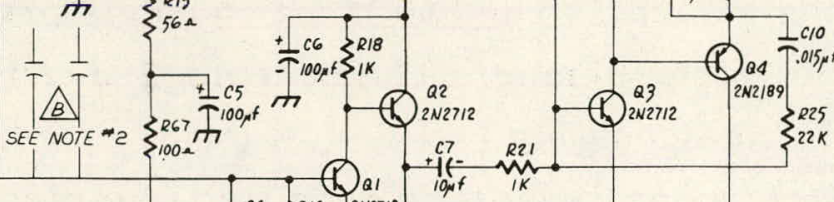

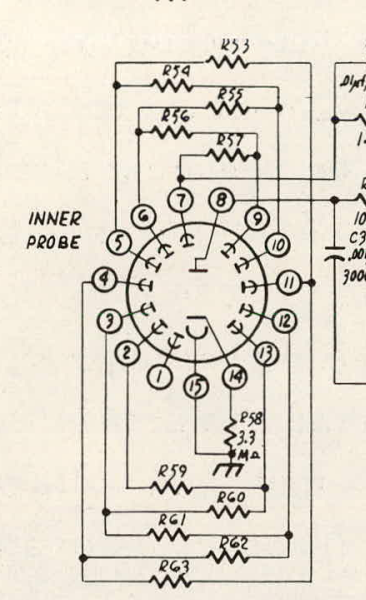

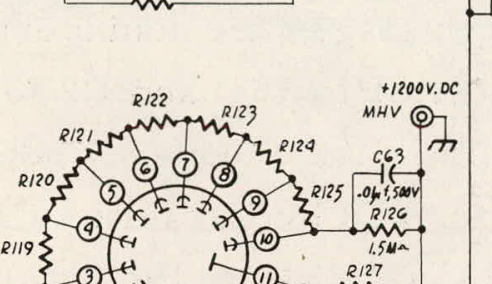

(1)

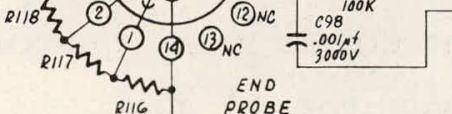
$\sum_{i k}^{\text {20o }}$

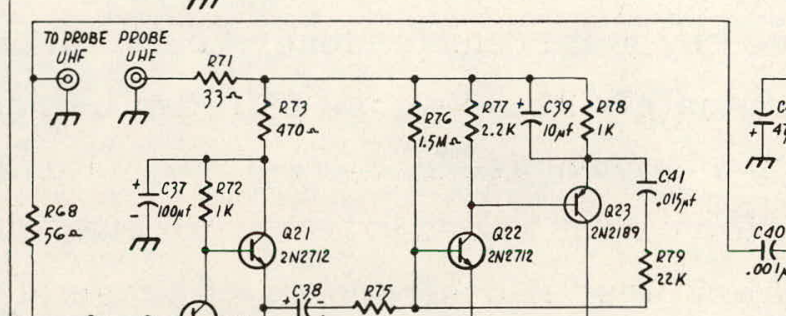

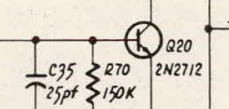
$\xi_{i=1}^{n+\infty}$

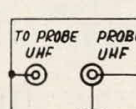

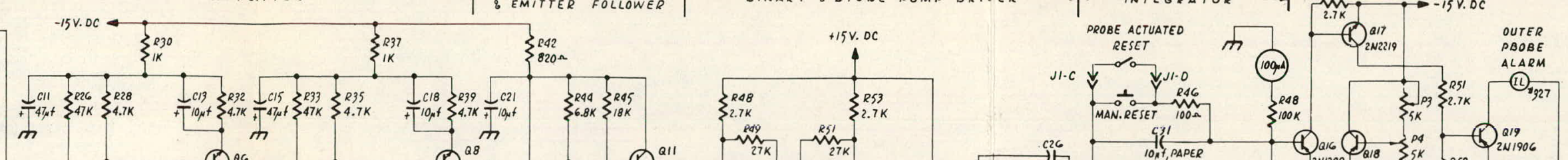

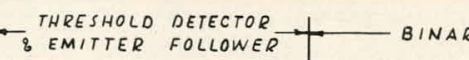

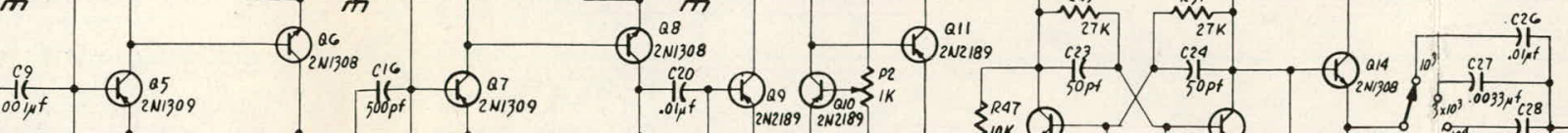

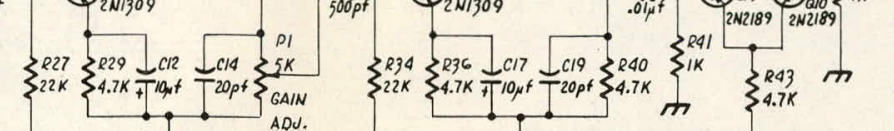

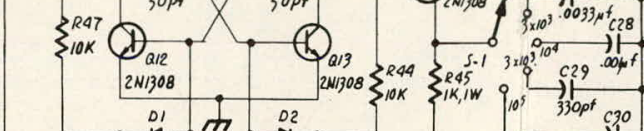<smiles>[Li]</smiles>
.

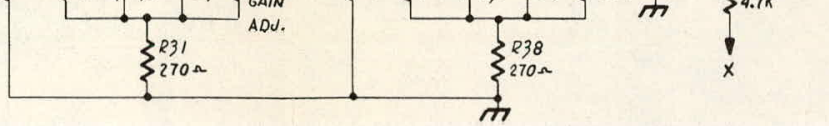

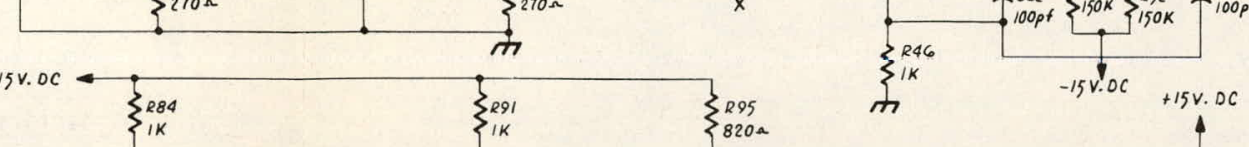

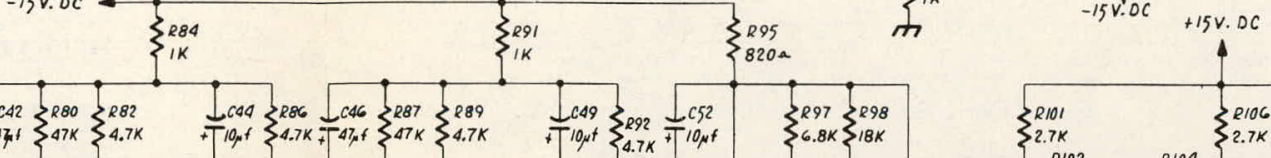

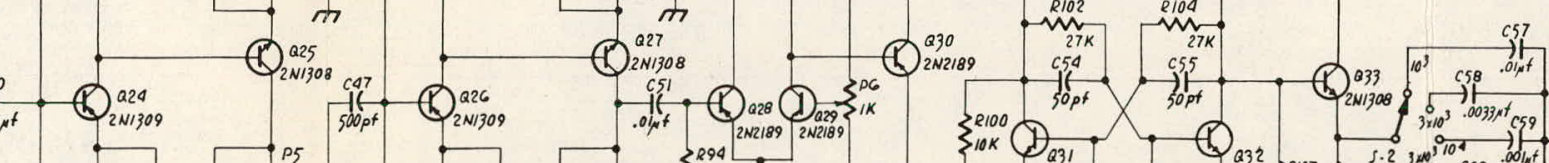

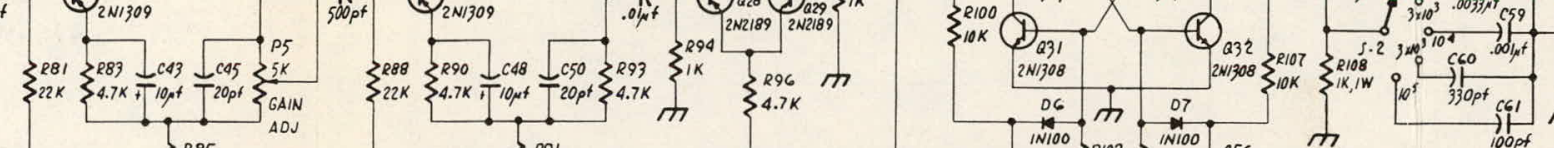

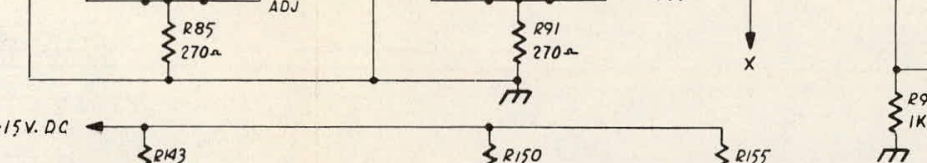

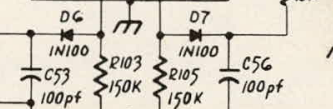

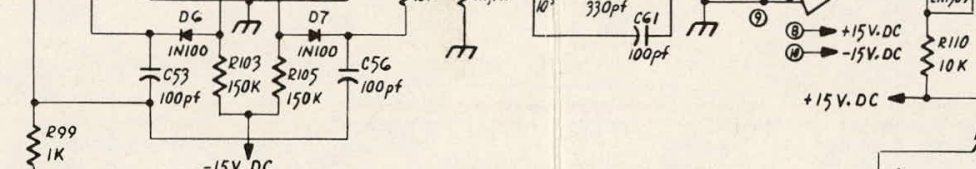

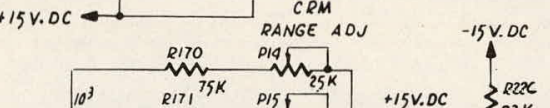

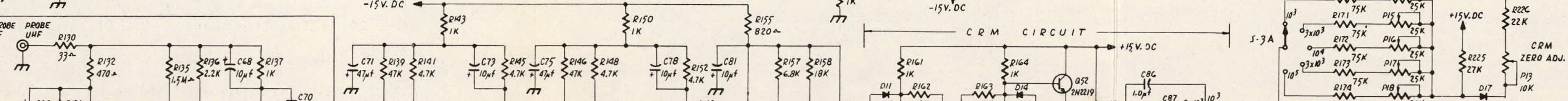

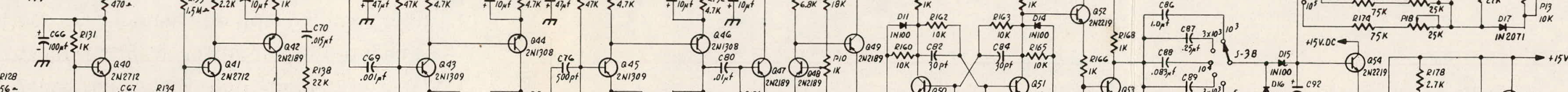

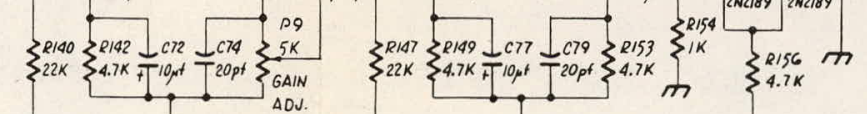

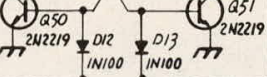

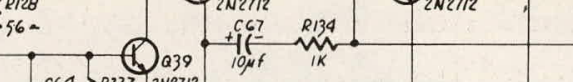

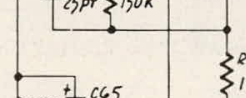

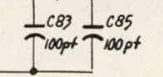
in

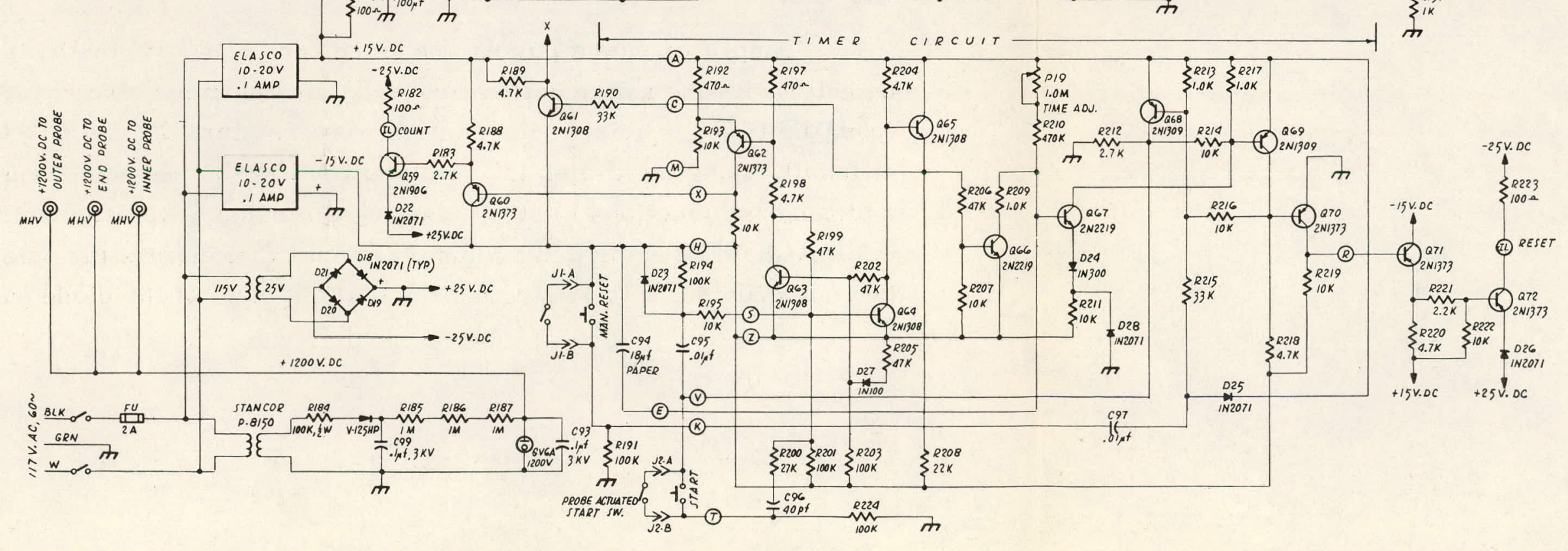

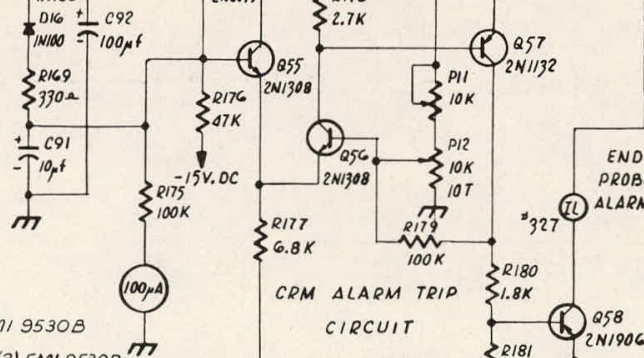

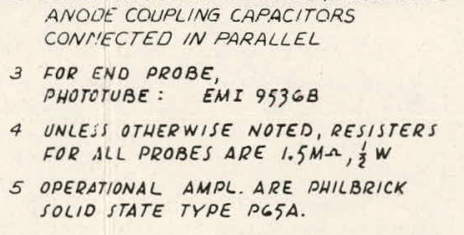
$\sum_{22.7 \times} \pitchfork$ 
the main instrument. The two main channels provide an indication of total count in the $15 \mathrm{sec}$ period. The nosepiece channel provides continuous indication of the counting rate. Voltages, corresponding to the count or counting rate, operate voltage sensitive trip circuits to provide alarm activation.

Each preamplifier is a charge sensitive, two transistor stage followed by a current feedback, cable driving stage with a voltage gain of approximately 22 . Voltage gain can be reduced by reducing the value of R25, the current feedback resistor. Resistor R17 (in series with the amplifier output impedance) terminates the cable to permit use of long coaxial cables, if desired. Each stage of the preamplifier provides voltage inversion so the overall gain is noninverting; this results in a negative-output pulse. In the main instrument, additional voltage gain and frequency bandwidth limiting is provided by two feedback-pair stages with an attenuator to control channel gain. Both stages are noninverting, and the attenuation is provided by potentiometers P1, P5, and P9 for the outer, inner, and nosepiece channels respectively. Low frequency noise is attenuated by the differentiating network formed by Capacitor C16 and the parallel combination of bias resistors R33 and R34 for the outer channel (similar for the other channels). This time constant is approximately $1 \mathrm{\mu sec}$, corresponding to a lower cutoff frequency of approximately $150 \mathrm{kHz}$.

Amplifier output pulses are gated "on" and "off" by the threshold detector with the gating action controlled by the timer circuit. Point $X$ from the timer provides bias current to transistors Q9 and Q10 (outer channel) during the timing interval and reverse-biases both transistor emitter base junctions to stop pulse transmission. Negative puls es from the threshold detector drive a binary circuit that divides the pulse rate by two and provides 0 to $15 \mathrm{~V}$ transitions to the input of the diode pump network. 
For the outer and inner channels, the diode pumps operate into solid state operational amplifier ${ }^{* *}$ integrators to integrate the count. . The nosepiece channel diode pumps operate a count-rate circuit that features a bootstrap voltage reference point for the recharging diode (D16) in the pump. This provides a 0 to $10 \mathrm{~V}$ output without the loss of linearity normally associated with a diode pump. For the count integrator circuits, the diodes operate into ground and virtual ground potential such that the output voltage rises linearly with a constant charge transferred to the integrating capacitor during each positive voltage transition at the input. Silicon diode temperature coefficient is about $2 \mathrm{mV} /{ }^{\circ} \mathrm{C}$ giving an overall coefficient for the two diodes of $+4 \mathrm{mV} /{ }^{\circ} \mathrm{C}$ or $0.04 \%$ of full scale per degree.

Transistor voltage trip circuits observe the 0 to $-10 \mathrm{~V}$ output of the two integrators and the 0 to $+10 \mathrm{~V}$ of the count-rate circuit output. For the outer channel, the trip level voltage is set (at the base of Q18) with a 10 turn potentiometer that reverse-biases the emitter-base junction of Q16 for integrator outputs below the trip level. When the output voltage exceeds the trip setting by a small amount, Q17 conducts and turns "on" " Q19 and the display lamp.

During the pulse counting interval following actuation of the start switch, the timer circuit energizes a "counting" lamp on the front panel and activates electronic gates to pass pulses in the inner and outer channels. After the prèset time has elapsed, the timer energizes the "reset" lamp on the front panel and turns off the gates. A stable electronic RC timing circuit was developed to provide an accurate $15 \mathrm{sec}$ time base. The timer capacitor output voltage with respect to the $-15 \mathrm{~V}$ bus is (in volts) $V_{c}=30\left(1-e^{\frac{-t}{T}}\right)$, where $\mathrm{T}=\mathrm{RC}$. A voltage comparator tests this voltage and trips at $\mathrm{V}_{\mathrm{c}}=15 \mathrm{~V}$ (or $\mathrm{t}=0.692 \mathrm{~T} \mathrm{sec}$ ). The time constant, $(T)$, is adjustable from 9 to $28 \mathrm{sec}$ and is usually set for a $15 \mathrm{sec}$ time base.

* Model P65A amplifier, Philbrick Co. 
A paper dielectric capacitor was used to insure negligible leakage current compared to the minimum charging current of $15 \mu \mathrm{A}$. The voltage comparator current and discharge path current combined are less than $20 \mathrm{nA}$ during the time interval; this is negligible compared to the charging current.

A portion of Figure 4 details the timer circuit. Assume the circuit was reset, started, and the timing interval was initiated. Time base capacitor, C94, is connected between Pins $\mathrm{H}(-15 \mathrm{~V})$ and $\mathrm{E}$. Pin $\mathrm{E}$ is the output for the charging current from the $+15 \mathrm{~V}$ bus (Pin A) through P19 and R210. The voltage drop from $P$ in $E$ to ground starts at $-15 \mathrm{~V}$ and charges toward $+15 \mathrm{~V}$ and forward-biases $\mathrm{Q} 67$ at slightly above ground potential. During this period, transistor $\mathrm{Q} 66$ is nonconducting. At the end of the time interval, Q67 turns on and sets binary Q68-Q69 such that Q69 is on. Then sequentially, Q70 turns off; and Q71, Q72, and the reset lamp turn on. The collector of $\mathrm{Q} 68$ in going from on to off provides a $-15 \mathrm{~V}$ transition $(+15$ to $0 \mathrm{~V})$ at Pin V. This transition is differentiated to provide a $-15 \mathrm{~V}$ pulse at Pin S thereby turning Q64 off, Q65 on, and Q66 on (which discharges the timing capacitor through Q66.and R209). In addition, the Q65 transition turns on $\mathrm{Q} 61$, providing $-15 \mathrm{~V}$ at Point $\mathrm{X}$ which turns off the electronic gates. Transistor Q64, which initiates the stated action, forms a binary with transistor Q63. This binary also controls the count lamp through the lamp driver transistors (Q59, Q60, and Q62). A "start" pulse turns Q64 on again. to initiate a new time cycle.

CONCLUSIONS

The described instrument is now being used to monitor standard. Hanford face masks for beta-gamma contamination. To date, the only difficulties have been minor pinholes (easily repaired) occurring in the aluminized Mylar covering over the scintillators. General operation appears to be successful and three masks can be monitored per'minute.

ACKNOWLEDGEMENT

The authors gratefully acknowledge the efforts of E. W. Groff for machining and fabricating the Lucite light pipes and for his assistance with the mechanical portions of the instrument. 


\section{ONSITE DISTRIBUTION}

Copy Number

Pacific Northwest Laboratory.

1

2

3

J. M. Atwood

W. J. Bair

E. A. Berreth

D. P. Brown

A. C. Case

L. J. Chockie

$7-8 \quad$ G. D. Crouch
$9 \quad$ G. E. Driver

10

G. F. Garlick

N. C. Hoitink

11

12

13

H. A. Meloeny

R. F. Palmer

J. L. Palotay

R. S. Paul

L. D. Philipp

N. S. Porter

F. L. Rising

G. M. Rolph

L. C. Schwendiman

20

$21-22$

E. M. Sheen

23

$24-34$

J. C. Spanner

35

36

37

38

$39-43$

44

45

W. G. Spear

A. J. Stevens

A. M. Unruh

E. E. Utz

D. C. Worlton

Technical Information Files

Technical Publications - 300 Area

Technical Publications - 700 Area

General Electric Company

46

47

48

F. E. Adley

C. J. Berglund

G. E. Cunningham

$49-52$

B. B. Evans

53

J. C. Glover

54

J. E. Kaveckis

55

56

L. M. Knights

M. T. Slind

M. L. Smith

57

GETA File Copy. 
ONSITE DISTRIBUTION (Contd.)

Copy Number

Richland Operations Office

59

Technical Information Library

60

R. K. Sharp 